\title{
Interactions of mixed organic contaminants in uptake by rice seedlings
}

\author{
Yuhong $\mathrm{Su}^{\mathrm{a}}$, Yongguan $\mathrm{Zhu}^{\mathrm{b}}$, Yongchao Liang ${ }^{\mathrm{c}, \mathrm{d}, *}$ \\ ${ }^{a}$ Chemistry Department, Xinjiang University, Urumqi 830046, PR China \\ ${ }^{\mathrm{b}}$ Research Center for Eco-Environmental Sciences, Chinese Academy of Sciences, Beijing 100085, PR China \\ ${ }^{\mathrm{C}}$ Key Laboratory of Oasis Eco-agriculture, College of Agriculture, Shihezi University, Shihezi, 832003 Xinjiang, PR China

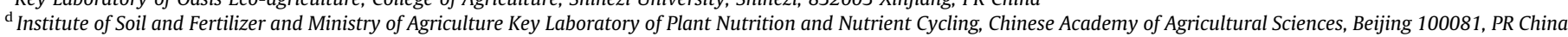

\section{A R T I C L E I N F O}

\section{Article history:}

Received 10 July 2008

Received in revised form 14 October 2008

Accepted 30 October 2008

Available online 17 December 2008

\section{Keywords:}

Plant uptake

Hydroponic solution

Organic contaminants

Rice seedlings

Transpiration rate

\begin{abstract}
A B S T R A C T
Uptakes of $o$-chlorophenol (CP), 2,4-dichlorophenol (DCP), trichloroethylene (TCE), and atrazine (ATR), as single and mixed contaminants, by roots and shoots of rice seedlings (Oryza sativa L.) from hydroponic solutions were measured following a 48-h exposure of plant roots. As single contaminants, the concentrations of $\mathrm{CP}, \mathrm{DCP}$, and ATR in rice roots and shoots increased significantly with increasing concentrations in external solutions; however, TCE concentrations in rice roots and shoots decreased with increasing external TCE concentration or the exposure time. The observed bioconcentration factors (BCFs) of $\mathrm{CP}$ and DCP with roots and the BCF of ATR with shoots approximated the equilibrium values according to the partition-limited model. The BCF of DCP with shoots was about $30 \%$ of the partition limit, due to insufficient water transport into plants for DCP. In the ATR-CP-DCP mixed system, the BCFs of CP and DCP with both roots and shoots decreased significantly with increasing contaminant concentrations due to the enhanced mixed-contaminant phytotoxicity, as manifested by the greatly reduced plant transpiration rate. In the ATR-CP-DCP mixture system, the BCFs of ATR with roots at low concentrations were comparable with those for ATR alone, whereas the BCFs increased at high concentrations for an unknown reason. In the TCE-DCP system, TCE concentrations in roots increased with increasing TCE in external solutions, while TCE concentration in shoots stayed steady because of the strong TCE exchange at the air-leaf interface. The BCF of DCP with roots was comparable with that of DCP alone because there was no significant effect of added TCE on the plant transpiration rate.
\end{abstract}

(c) 2008 Elsevier Ltd. All rights reserved.

\section{Introduction}

Food crops are susceptible to contamination by various pesticides and organic wastes when exposed to a polluted source, as these chemicals may be transported to varying extents into crop tissues (Harris and Sans, 1967; Walker, 1972; Li et al., 2002; Wild et al., 2006). The need for better understanding the mechanism and influential factors on plant uptake has prompted a series of studies on the plant-uptake process in recent times (Riederer, 1990; Paterson et al., 1994; Trapp, 1995; Trapp and Mathies, 1995; Burken and Schnoor, 1997; Weiss, 2000; Li et al., 2002, 2005; Wild et al., 2005). Analyses of the concentrations of nonionic contaminants in plants in relation to the external levels in water (or soil solution) from extensive sources have revealed that these contaminants enter plants largely via a passive (i.e., partition) process (Briggs et al., 1982; Chiou et al., 2001; Trapp, 2004; Su and Zhu, 2006). The magnitude and efficiency of plant uptake depends in principle on con-

\footnotetext{
* Corresponding author. Address: Key Laboratory of Oasis Eco-agriculture, College of Agriculture, Shihezi University, Shihezi, 832003 Xinjiang, PR China. Tel.: +86106891 8657; fax: +86106897 122 .

E-mail address: ycliang@caas.ac.cn (Y. Liang).
}

taminant level and properties, plant species/composition, exposure time, and other variables (Briggs et al., 1982; Chiou et al., 2001; Trapp, 2004; Wild et al., 2005). Previously, we have studied the uptake of atrazine by rice seedlings from nutrient solution with and without coexisting organic and metal-ion species (Su et al., 2005; Su and Zhu, 2006). It was found that the uptake of atrazine (ATR) by rice seedlings was largely unaffected by co-existing organic compounds and appeared to proceed essentially by passive (i.e., partition) mechanism. In current literature, there have been few studies comparing contaminant levels in different plant parts and most published studies have been conducted in single- rather than mixed-contaminant systems. In view of the occurrence of various organic contaminants in natural systems, more extensive tests are necessary to understand the interactions of organic contaminants on their concurrent uptakes by plants.

ATR is one of the most intensively used herbicides in agricultural practices (e.g., maize production). Residues of ATR spread across the land surface and soil-water interface to the groundwater region (Belluck et al., 1991; Burkart and Kolpin, 1993). Previous studies indicated that ATR can greatly reduce the transpiration rate of rice seedlings at low concentrations ( $\mathrm{Su}$ and $\mathrm{Zhu}, 2006$ ). ATR applied to rotation fields significantly affects the growth of rice in 
China, as the rice seedlings accumulate significant levels of ATR from soil solution. On the other hand, trichloroethylene (TCE) has been found in groundwater and many surface waters as a result of the manufacturing, use, and disposal of the chemical; phenolic compounds, such as o-chlorophenol (CP) and 2,4-dichlorophenol (DCP), may enter surface water upon the discharge of industrial wastewaters. As such, mixtures of these organic compounds may occur in agricultural fields.

In the present study, the uptakes of ATR, CP, TCE, and DCP from nutrient solutions as single and mixed contaminants by seedlings of a rice species have been determined for better understanding the interaction of co-existing contaminants on the plant uptake process. The concentrations for each parent contaminant in plant roots and shoots were quantified separately and analyzed in terms of plant transpiration rates and contaminant partition coefficients with individual cut-dried roots and shoots. This novel approach provides a unique basis for validating the plant-uptake data. Rice plant is chosen for investigation because it is a staple food crop in China that is susceptible to contamination by various pesticides and other chemicals from local pollution sources. Furthermore, there are few published studies on rice-plant uptake of anthropogenic organic substances in the literature. While ATR (a widely used herbicide and a weak base), chlorophenols (common wastewater contaminants and weak acids) and TCE (a volatile organic compound) represent different chemical types, they also exhibit significantly different partition coefficients to aid in the evaluation of the plant-uptake process.

\section{Materials and methods}

\subsection{Preparation of rice seedlings}

Seeds of Oryza sativa L. Chinese rice cv. Jiahua-1 were disinfected in $30 \% \mathrm{H}_{2} \mathrm{O}_{2}$ (wt:wt) solution for $10 \mathrm{~min}$, followed by a thorough washing with deionized water. The seeds were germinated in moist perlite in an incubator at $25{ }^{\circ} \mathrm{C}$. Seven days after germination, the seedlings were transferred to a nutrient solution for continuing growth. Three weeks later, uniform seedlings were selected and transplanted to polyvinylchloride (PVC) pots $(7.5 \mathrm{~cm}$ in diameter and $14 \mathrm{~cm}$ in height) for uptake experiments with a density of one plant per pot; each pot containing $500 \mathrm{ml}$ nutrient solution with selected contaminants. The composition of the nutrient solution for the experiment was as follows: $5 \mathrm{mM} \mathrm{NH}_{4} \mathrm{NO}_{3}$,

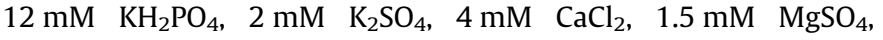
$100 \mu \mathrm{M} \mathrm{Fe}(\mathrm{III})$-ethylenediaminetetraacetic acid (EDTA), $10 \mu \mathrm{M}$ $\mathrm{H}_{3} \mathrm{BO}_{4}, 1.0 \mu \mathrm{M} \mathrm{ZnSO}_{4}, 1.0 \mu \mathrm{M} \mathrm{CuSO}_{4}, 5.0 \mu \mathrm{M} \mathrm{MnSO}_{4}, 0.5 \mu \mathrm{M} \mathrm{Na}_{2-}$ $\mathrm{MoO}_{4}, 0.2 \mu \mathrm{M} \mathrm{CoSO}$. The nutrient solution was changed once a week, and its $\mathrm{pH}$ value was adjusted to 5.5 using $0.1 \mathrm{M} \mathrm{KOH}$ or $\mathrm{HCl}$ solution.

\subsection{Treatments with contaminants}

Compounds used for plant-uptake studies, o-chlorophenol (CP), 2,4-dichlorophenol (DCP) and trichloroethylene (TCE) were all of analytical grade, and atrazine (ATR), were supplied by Dima Chemical Company, China (purity $>97 \%$ ), and used as received without further treatment.

In plant-uptake experiments, a series of three-seedling sets (grown three weeks in PVC pots) of comparable sizes were prepared, with their roots being immersed into same nutrient solutions (ca. $500 \mathrm{~mL}$ each). The nutrient solutions containing different added levels of given contaminants were held by a series of identical PVC cylinders. The cylinder was fitted with a PVC septum $(7.5 \mathrm{~cm}$ in diameter and $0.5 \mathrm{~cm}$ in thickness) with a hole drilled at its center $(1.5 \mathrm{~cm}$ in diameter $)$, through which the plant shoots extended into the external air. The section of the shoots passing through the septum hole was wrapped with sponge sheets to minimize the open space. This design prevented direct water evaporation from the nutrient solution into external air when the seedlings were in place. Hence, the mass of water transpired through plant shoots could be determined accurately by measuring the net weight change of the nutrient solution and plants.

In uptake studies of single contaminants, the initial contaminant concentrations in nutrient solutions were set at $10,20,40$, 80 , and $160 \mathrm{mg} \mathrm{L}^{-1}$ for CP; $5,10,20,40$, and $80 \mathrm{mg} \mathrm{L}^{-1}$ for DCP; 2 , 4,8 , and $16 \mathrm{mg} \mathrm{L}^{-1}$ for TCE; and 2, 4, 6, 8, and $10 \mathrm{mg} \mathrm{L}^{-1}$ for ATR. In uptake studies with $\mathrm{CP}, \mathrm{DCP}$, and ATR as mixed contaminants, the initial CP/DCP/ATR concentrations were set at 10/5/2, 20/10/ $4,40 / 20 / 6,80 / 40 / 8$, and $160 / 80 / 10 \mathrm{mg} \mathrm{L}^{-1}$. In uptake studies with DCP and TCE as mixed contaminants, the initial DCP/TCE concentrations were set at $0.5 / 2,1 / 4,2 / 8$, and $4 / 16 \mathrm{mg} \mathrm{L}^{-1}$.

Experiments were carried out for $48 \mathrm{~h}$ in an environmentallycontrolled growth chamber that maintained a daily 14-h light period $\left(260-350 \mu \mathrm{mol} \mathrm{m}^{-2} \mathrm{~s}^{-1}\right)$ and $25^{\circ} \mathrm{C}$ for daytime and $20^{\circ} \mathrm{C}$ for nighttime. The relative humidity was set at $70 \%$.

\subsection{Water transpiration rate}

The amounts of water transpired by plants over the 48-h-period were determined based on the cumulated weight losses of the plant-solution systems by measuring their weight changes at 1$3 \mathrm{~h}$ intervals between 7:00 am and 11:00 pm. After each measurement, the amount of water lost by plant transpiration was replenished with fresh nutrient solution to maintain the total solution volume nearly constant at ca. $500 \mathrm{~mL}$. By this method, the error in amounts of water transpiration was minimized. It also enabled a quick detection of the change in plant transpiration rate when the plant growth was strongly affected by the contaminant toxicity. From the cumulated water-loss weights and the measured fresh plant weights after 48-h exposure, the plant transpiration rates $(G)$ (as g water/g fresh plant weight) were then calculated.

\subsection{Plant-contamination levels}

After harvest, the studied plants were removed from the nutrient solutions, rinsed with distilled water, blotted dry with tissue paper, and sectioned into roots and shoots, and the relative weight fractions of fresh roots and shoots $(F W)$ were determined. The samples were ground with a mortar and pestle and subsequently extracted and analyzed for contaminant levels. The detailed analytical procedures are presented later. Control seedlings (grown in solutions without contaminants over the same period) were then removed and sectioned into roots and shoots; the relative weight fractions of fresh roots and shoots (FW) were determined. Halves of the sectioned roots and shoots of the control plants were dried in an oven $\left(60-70{ }^{\circ} \mathrm{C}\right)$ for $24 \mathrm{~h}$ to determine their respective water contents.

\subsection{Sorption with cut-dried roots/shoots}

The combined cut-dried roots or shoots of control plants were ground into small particle sizes (passing 100 mesh), which were subsequently used to determine the $K_{\text {pom }}$, the contaminant partition coefficient between plant organic matter and water. To determine the $K_{\text {pom }}$, fixed amounts of dried ground roots or shoots $(0.2 \mathrm{~g})$ were added to a series of nutrient solutions $(10 \mathrm{~mL})$ containing different initial levels of a given contaminant; the suspensions were equilibrated for $48 \mathrm{~h}$ and contaminant concentrations in roots (or shoots) and water were determined after this equilibration period. Average values from duplicate samples were used to construct the sorption isotherms. This equilibration period was 
found sufficient for establishing contaminant equilibrium between dried-ground roots/shoots and water.

\subsection{Analyses of the contaminants}

Quantification of CP, DCP, TCE and ATR levels in water from all experiments was achieved by extracting aliquots of respective water samples $(0.5 \mathrm{~mL})$ twice with $n$-hexane $(3.0 \mathrm{~mL})$, with the combined extracts analyzed for each contaminant by gas chromatography (GC). To determine the levels of these contaminants in fresh roots and shoots, the cut plant samples from each of the three seedlings were weighed, ground, and extracted four times with mixed petroleum ether/methylene dichloride (6.5/3.5, v:v; $20 \mathrm{~mL}$ ), with the combined extracts further cleaned up by passing through a Florisil column $(1 \mathrm{~cm} \times 2.5 \mathrm{~cm})$ prior to the GC analyses. The contaminant levels with roots or shoots measured separately with the three plants were then averaged. The quantification and separation of CP, DCP, TCE and ATR as single and mixed contaminants were achieved by an Agilent 6820 gas chromatograph equipped with a ${ }^{63} \mathrm{Ni}$ electron capture detector (ECD) using a HP5 capillary column $(0.32 \mathrm{~mm} \times 30 \mathrm{~m} \times 0.25 \mu \mathrm{m})$ and a split injection mode.

The average recoveries of CP, DCP, TCE and ATR from plant samples, based on analyses of equilibrated mixtures of contaminants in previously unexposed seedlings, were $96.5 \pm 9.3 \%, 83.9 \pm 7.2 \%$, $65.6 \pm 7.9 \%$ and $90.3 \pm 6.4 \%(n=5)$, respectively. For the water samples, the respective recoveries were $91.4 \pm 8.0 \%, 92.7 \pm 5.3 \%$, $95.8 \pm 1.2 \%$ and $100.7 \pm 3.1 \%(n=5)$. The measured levels of contaminants in plant and water samples were not corrected for the recoveries.

\section{Results and discussion}

\subsection{Plant uptake: single contaminants}

The observed CP, DCP and ATR concentrations were much higher in seedlings (roots and shoots) than in external nutrient solutions and increased with increasing contaminant concentration in the external solution. Linear relations existed between $C P, D C P$, ATR concentrations in roots/shoots and in nutrient solution (BCFs are listed in Table 1 as constant values), which indicated that the contaminants entered the roots by passive processes and then moved with plant transpiration streams to shoots and accumulated into the plant organic matter, such as lipids (Briggs et al., 1982; Chiou et al., 2001; Li et al., 2005). However, TCE concentration in rice seedlings (roots and shoots) decreased with increasing TCE concentration in the external solution, as depicted in Fig. 1. These results indicated that there existed a different transport

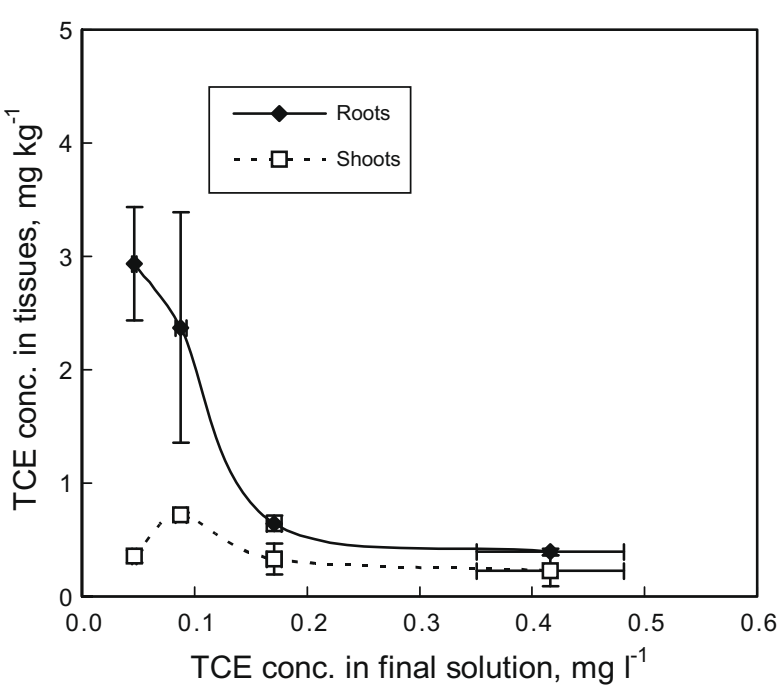

Fig. 1. Concentrations of TCE in rice tissues and nutrient solution in plant uptake of TCE alone. Error bars represent the standard error (SE).

and accumulation mechanism for TCE with rice seedlings as compared to other contaminants. It was reported that TCE could be taken up via shoots from air (foliar uptake) and transported to roots (Schroll et al., 1994). As a result, TCE was detected in the external solutions of control treatments that were not contaminated with TCE before the experiment. Due to its high solubility (1100 $\mathrm{mg} \mathrm{L}^{-1}$ ) and volatility, TCE entering rice roots via mainly a passive process could be easily translocated with plant transpiration streams to shoots and volatilized along with water into the air, resulting in the lower accumulation in rice seedlings (Fig. 1). On the other hand, the foliar uptake of TCE by shoots was contemporaneous with volatilization and proceeded in the direction of decreasing chemical potential (Simonich and Hites, 1994). Thus, the efficiency of TCE downward transport via phloem decreased with increasing TCE concentration in roots and in external solution, with the result that the BCF of TCE in rice seedlings decreased with increasing TCE concentration in external solution.

\subsection{Dry roots and shoots}

The sorption isotherms of CP, DCP, TCE and ATR with dry roots or shoots as sorbents were constructed. The respective $K_{\text {pom }}$ values derived from the isotherms for the three contaminants with roots and shoots and their standard errors (SE) are summarized in Table 1. Based on the $\mathrm{p} K_{\mathrm{a}}$ values $(8.56,7.85$ and 1.70 for CP, DCP and ATR,

Table 1

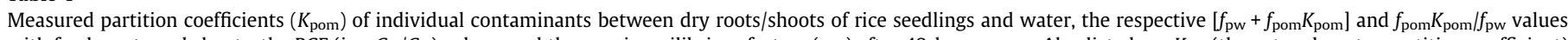

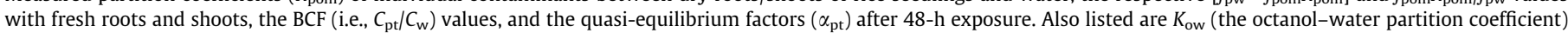
and $H_{\mathrm{c}}$ (the Henry constant) (torr $\mathrm{L} / \mathrm{mol}$ ) of the contaminants.

\begin{tabular}{|c|c|c|c|c|c|}
\hline Contaminant & & $\mathrm{CP}$ & DCP & ATR & TCE \\
\hline \multirow[t]{2}{*}{$K_{\mathrm{pom}}( \pm \mathrm{SE})$} & Roots & $27.8( \pm 2.3)$ & $132( \pm 5.5)$ & $36.8( \pm 2.8)$ & $21.6( \pm 3.2)$ \\
\hline & Shoots & $12.1( \pm 2.1)$ & $47.8( \pm 3.4)$ & $20.1( \pm 1.7)$ & $13.6( \pm 1.5)$ \\
\hline \multirow{2}{*}[f_{\mathrm{pw}}+f_{\mathrm{pom}}K_{\mathrm{pom}}]{$^{\mathrm{a}}$} & Roots & 3.55 & 13.4 & 4.40 & 2.96 \\
\hline & Shoots & 2.64 & 7.93 & 3.83 & 2.86 \\
\hline \multirow[t]{2}{*}{$\mathrm{BCF}( \pm \mathrm{SE})$} & Roots & $3.17( \pm 0.48)$ & $14.0( \pm 2.81)$ & $1.26( \pm 0.06)$ & - \\
\hline & Shoots & $1.87( \pm 0.62)$ & $2.54( \pm 1.16)$ & $4.95( \pm 0.18)$ & - \\
\hline \multirow[t]{2}{*}{$\alpha_{\mathrm{pt}}( \pm \mathrm{SE})^{\mathrm{a}}$} & Roots & $0.89( \pm 0.13)$ & $1.04( \pm 0.21)$ & $0.30( \pm 0.01)$ & - \\
\hline & Shoots & $0.71( \pm 0.23)$ & $0.32( \pm 0.15)$ & $1.33( \pm 0.05)$ & - \\
\hline $\log K_{\mathrm{ow}}$ & & 2.15 & 3.30 & 2.71 & 2.42 \\
\hline$H_{\mathrm{c}}\left(\times 10^{-6}\right)$ & & 10.3 & 2.8 & 2.6 & 9100 \\
\hline
\end{tabular}

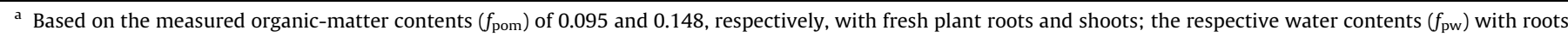
and shoots are 0.905 and 0.852 . 
respectively) and the fixed solution $\mathrm{pH}$ (5.5), the measured isotherms are essentially for the unionized contaminant species. The water contents $\left(f_{\mathrm{pw}}\right)$ for roots and shoots of the rice seedlings, calculated from water losses upon drying of the fresh samples, are 0.905 and 0.852 , respectively for the roots and shoots. Computed by differences, the respective organic-matter contents $\left(f_{\text {pom }}\right)$ are 0.095 and 0.148 for roots and shoots. The high isotherm linearity with these contaminants is evidence for a partition-equilibrium effect between (dry) roots/shoots and water (Barbour et al., 2005).

For nonionic organic contaminants with selective plant seedlings, where the plants and external water may or may not be close to equilibrium, a quasi-equilibrium partition model may be applied to relate the concentration in plants (or in a plant part) at a given point in time with that in the external water (or the soil water) (Chiou et al., 2001), namely

$C_{\mathrm{pt}}=\alpha_{\mathrm{pt}} C_{\mathrm{w}}\left[f_{\mathrm{pw}}+f_{\mathrm{pom}} K_{\mathrm{pom}}\right]$

where $C_{\mathrm{pt}}$ is the plant contaminant concentration on the freshweight basis and $C_{\mathrm{w}}$ is the concentration in the external water; $f_{\mathrm{pw}}$ and $f_{\mathrm{pom}}$ are the respective weight fractions for plant water and plant organic matter; $K_{\text {pom }}$ is the contaminant partition coefficient between plant organic matter and plant water; and $\alpha_{\mathrm{pt}}(\leqslant 1)$ is the quasi-equilibrium factor, the ratio of contaminant levels in plant water and external water at a specific point in time. The $C_{\mathrm{pt}}$-to- $C_{\mathrm{w}}$ ratio, at any point in time or any $\alpha_{\mathrm{pt}}$, is termed the bioconcentration factor (BCF). When the uptake reaches equilibrium, the $\mathrm{BCF}$ is then equal to $\left[f_{\mathrm{pw}}+f_{\mathrm{pom}} K_{\mathrm{pom}}\right]$.

From the measured $f_{\mathrm{pw}}, f_{\mathrm{pom}}$, and $K_{\mathrm{pom}}$, the $\left[f_{\mathrm{pw}}+f_{\mathrm{pom}} K_{\mathrm{pom}}\right]$ term in Eq. (1) could then be quantified, as listed in Table 1, for the subsequent analysis of contaminant uptakes by roots and shoots. The quasi-equilibrium factors $\left(\alpha_{\mathrm{pt}}\right)$, which were calculated using the measured BCFs and the calculated $\left[f_{\mathrm{pw}}+f_{\mathrm{pom}} K_{\mathrm{pom}}\right]$ values in Table 1 , are also listed in Table 1 . Results showed that a higher BCF was observed for DCP than for CP and ATR, consistent with their determined $K_{\text {pom }}$ values; the correlation between BCF and $K_{\text {pom }}$ for CP and ATR is less significant because their BCF and $K_{\text {pom }}$ values are relatively comparable. The calculated $\alpha_{\mathrm{pt}}$ values with roots are reasonably close to 1 for $\mathrm{CP}$ and DCP, indicating that the concentrations accumulated in roots are near the equilibrium limits; for ATR, with $\alpha_{\mathrm{pt}} \cong 0.30$, the level in roots is only about half the equilibrium limit for unknown reasons. A similar effect has been noted by Briggs et al. (1982) for certain polar (hydrophilic) herbicides (e.g., aldoxycarb) with barley roots, the effect being attributed to the chemical's poor efficiency in passing through plant-lipid membranes. Whether the same occurs for ATR with rice seedlings remains to be substantiated.

The contaminant levels with plant shoots provide a sensitive measure of the contaminant transport into upper plant parts driven by the transpiration stream (Table 2 ). The calculated $\alpha_{\mathrm{pt}}$ values with shoots from the observed BCFs, as shown in Table 1, appear to reflect to a good extent the trend for plant passive (partition) up- take. For both CP and ATR, which are more hydrophilic than DCP, the observed $\alpha_{\mathrm{pt}}$ values were higher than that of DCP, which suggested that an efficient systemic water transport (i.e., the upward movement via xylem and downward movement via phloem) occurred that brought the contaminant levels to near equilibrium limits with the external water. The lower $\alpha_{\mathrm{pt}}$ for DCP with shoots (0.32) is expected because DCP has a much higher equilibrium BCF such that the amount of external water containing DCP transported into the plants was insufficient for DCP to satisfy the equilibrium limit with the shoots.

\subsection{Plant uptake: mixed contaminants}

Previous studies have shown that the restraining effect of ATR on plant transpiration rate was far greater than CP and DCP as individual species ( $\mathrm{Su}$ and $\mathrm{Zhu}, 2006$ ). The associated plant transpiration rates for the mixture systems are given in Table 2 . Results showed that coexisting contaminants, $\mathrm{CP}$ and DCP, significantly reduced the effect of ATR on plant transpiration at low concentration, but increased it when the initial CP/DCP/ATR concentrations (in $\mathrm{mg} \mathrm{L}^{-1}$ ) were set at 40/20/6. The observed BCF values for ATR with roots were comparable with the corresponding values for singleATR systems (Table 1 and Fig. 2); however, the BCF values of ATR with shoots significantly increased with increasing ATR concentration in the external solution (Fig. 2). The observed BCF values for DCP with plant roots and shoots decreased quickly with increasing of DCP concentration in external solution at low mixed-contami-

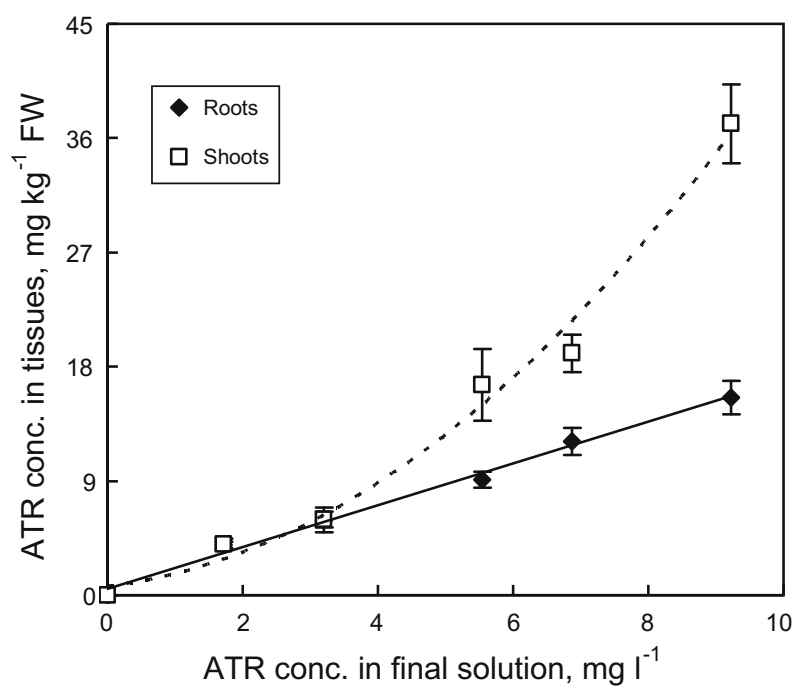

Fig. 2. Concentrations of ATR in rice tissues and nutrient solution in plant uptake of the $\mathrm{CP} / \mathrm{DCP} / \mathrm{ATR}$ mixture. Each point is the mean of three replicates. Error bars represent the SE.

Table 2

Relations between transpiration rates $(G)$ of rice seedlings and initial single and mixed contaminant levels in solutions $\left(C_{\mathrm{w}}^{\circ}\right)$ to which plant roots were exposed. ${ }^{\mathrm{a}}$

\begin{tabular}{|c|c|c|c|c|c|c|c|c|c|c|}
\hline & \multicolumn{4}{|c|}{ As mixed contaminants } & \multicolumn{6}{|c|}{ As single contaminants } \\
\hline & \multicolumn{4}{|l|}{$C_{\mathrm{w}}^{\mathrm{o}}$} & \multicolumn{2}{|l|}{$\mathrm{CP}$} & \multicolumn{2}{|c|}{ DCP } & \multicolumn{2}{|c|}{ ATR } \\
\hline & $\mathrm{CP}$ & DCP & ATR & $G$ & $C_{\mathrm{w}}^{\mathrm{o}}$ & G & $C_{\mathrm{w}}^{\mathrm{o}}$ & G & $C_{\mathrm{w}}^{\mathrm{o}}$ & $G$ \\
\hline Control plants & 0 & 0 & 0 & 8.50 & 0 & 8.50 & 0 & 8.50 & 0 & 8.50 \\
\hline \multirow[t]{5}{*}{ Exposed plants } & 10 & 5 & 2 & 7.92 & 10 & 7.67 & 5 & 7.49 & 2 & 5.96 \\
\hline & 20 & 10 & 4 & 7.29 & 20 & 6.70 & 10 & 5.69 & 4 & 5.43 \\
\hline & 40 & 20 & 6 & 3.71 & 40 & 7.20 & 20 & 6.09 & 6 & 5.24 \\
\hline & 80 & 40 & 8 & 5.21 & 80 & 6.48 & 40 & 5.96 & 8 & 4.54 \\
\hline & 160 & 80 & 10 & 4.94 & 160 & 6.04 & 80 & 4.51 & 10 & 4.42 \\
\hline
\end{tabular}

$C_{\mathrm{w}}^{\mathrm{o}}=$ initial contaminant concentration in solution $\left(\mathrm{mg} \mathrm{L}^{-1}\right)$.

${ }^{\mathrm{a}} G=$ mass of water transpired per unit fresh weight of the rice seedlings $\left(\mathrm{g} \mathrm{g}^{-1}\right)$. 
nant levels, while they stayed steady at high mixed-contaminant levels (Fig. 3). The observed BCF values for CP with plant shoots were slightly greater than those with plant roots, differing from those for single CP systems (Table 1 and Fig. 4). At low mixed-contaminant levels, the observed BCFs for $\mathrm{CP}$ with plant roots and shoots were far more than those for corresponding single-contaminant values (Fig. 4), showing that coexisting DCP and ATR at low concentrations promoted the accumulation of $\mathrm{CP}$ in plant organic components. At high mixed-contaminant levels, the BCF values for $\mathrm{CP}$ and DCP in both shoots and roots changed remarkably with exposure levels in solution (Figs. 3 and 4), while the BCF values for ATR with roots were largely independent of the exposure levels $\left(C_{\mathrm{w}}=2-10 \mathrm{mg} \mathrm{L}^{-1}\right)$ (Fig. 2). Over the low mixed CP-DCP-ATR levels, the amount of water transpired decreased somewhat to 7$8 \mathrm{~g} \mathrm{~g}^{-1}$ (relative to $8.5 \mathrm{~g} \mathrm{~g}^{-1}$ for the control species), so the plant growth was inhibited only slightly by the mixed contaminants relative to that of the control species (Table 2). The marked decrease in BCF was closely related to the toxicities of the mixed contaminants, as manifested by the nearly total inhibition of plant growth and a large decline in plant transpiration (down to $3.7-5.2 \mathrm{~g} \mathrm{~g}^{-1}$ ).

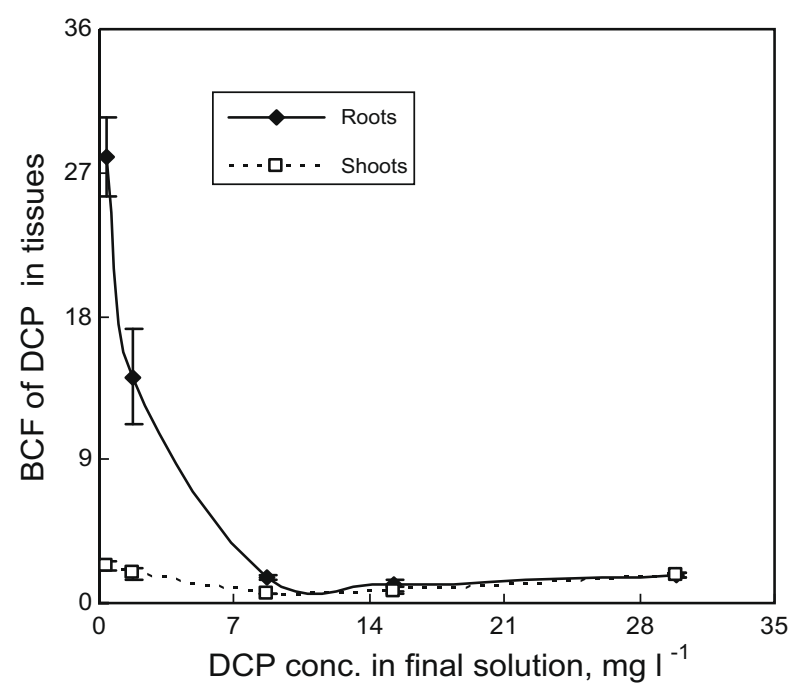

Fig. 3. The $B C F$ of $D C P$ with plant tissues from the $C P / D C P / A T R$ mixture uptake. Each point is the mean of three replicates. Error bars represent the SE.

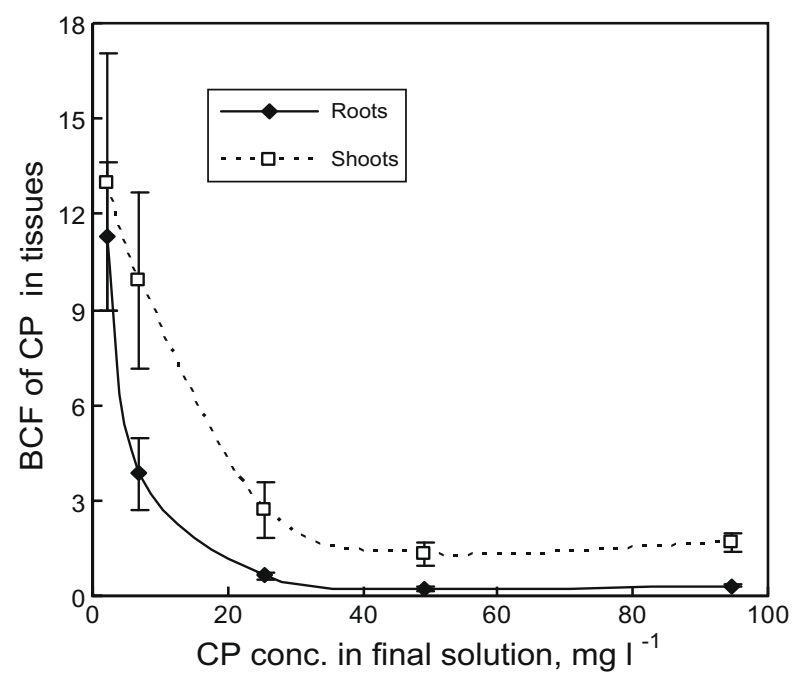

Fig. 4. The $B C F$ of $C P$ with plant tissues from the $\mathrm{CP} / \mathrm{DCP} / \mathrm{ATR}$ mixture uptake. Each point is the mean of three replicates. Error bars represent the SE.

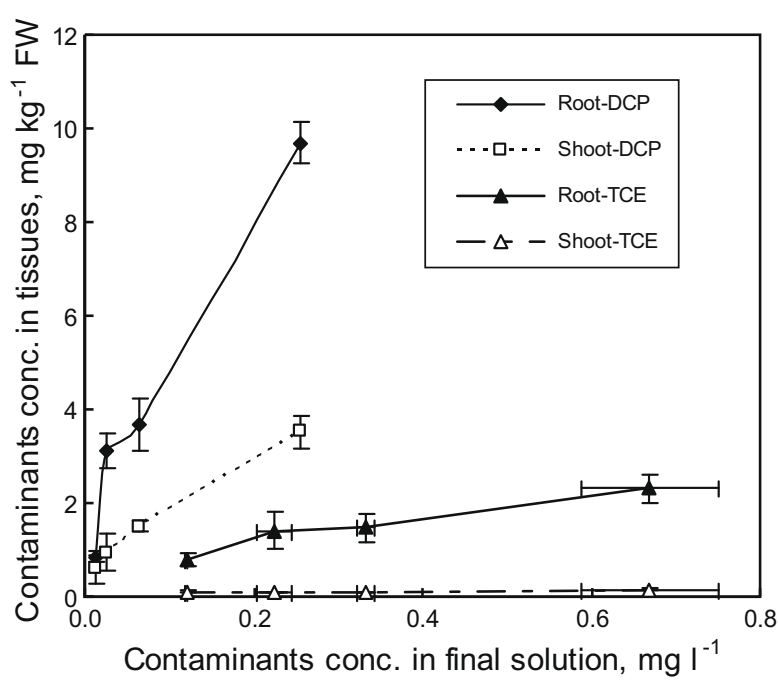

Fig. 5. Concentrations of TCE and DCP in rice tissues and nutrient solution in plant uptake of the TCE/DCP mixture. Each point is the mean of three replicates. Error bars represent the SE.

At low concentrations of the TCE-DCP mixture system, there was no significant difference between treatments of observed plant transpiration rates $(8.10 \pm 0.16 \mathrm{~g}$ water transpired per gram fresh weight of the rice seedlings). The BCFs for DCP in both shoot and roots decreased slightly with increasing level in solution (Fig. 5), but were far higher than those in both single-contaminant and mixed DCP-OP-ATR systems. The concentration of TCE in rice shoots and roots increased with increasing TCE concentration in the external solution (Fig. 5), suggesting that the co-existing DCP changed the accumulation of TCE in rice seedlings, as compared with single-contaminated system (Fig. 1). TCE was detected in the final nutrient solution, plant roots, and shoots of the control treatment that received no TCE or DCP in initial external solution; the BCF values of TCE were 82.7 with roots and 7.1 with shoots, which were far higher than observed in other treatments. These values indicated that TCE entered the nutrient solution through the foliar uptake by shoots, followed by a downward movement to roots and to the external solution.

As a whole, the measured BCFs for the mixed contaminant systems were complicated by the combined phytotocixity and other unknown effects, making the data evaluation and analysis much more difficult.

\section{Conclusions}

Most observed BCFs and $\alpha_{\mathrm{pt}}$ values for CP, DCP, and ATR at low exposure levels with roots and shoots of the rice seedlings could be well understood in terms of plant passive-uptake (partition) process. Data on the water and organic-matter contents of roots and shoots and contaminant partition coefficients with respective (dry) plant fractions enable the contaminant partition limits to be established for assessment of the plant-uptake efficiency. Under conditions where plants maintain a relatively healthy growth, the levels of accumulation in both roots and shoots for given contaminants are largely independent of other coexisting contaminants and the observed levels are reconcilable with the measured plant transpiration rates. When the contaminant phytotoxicity severely affects plant growth and transpiration, the plant uptake of contaminants declines. The uptake of more hydrophilic compounds (e.g., $\mathrm{CP})$ tends to more quickly approach the equilibrium limits than less hydrophilic compounds (DCP) over the same exposure period. This is because the attainment of equilibrium for the latter com- 
pounds requires more water transport to plants, especially to the upper plant parts, such as shoots. As illustrated, the rate of water transport into plants is a critical factor on the plant uptake of contaminants from a polluted water source.

\section{Acknowledgements}

This study was supported by the National Scientific Foundation of China (20667003) and by the Open Funding of the Key Laboratory of Oasis Eco-agriculture, Shihezi University (200703).

\section{References}

Barbour, J.P., Smith, J.A., Chiou, C.T., 2005. Sorption of aromatic organic pollutants to grasses from water. Environ. Sci. Technol. 39, 8369-8373.

Belluck, D.A., Benjamin, S.L., Dawson, T., 1991. Groundwater contamination by atrazine and its metabolites: risk assessment, policy, and legal implications. American Chemical Society. Ann. Proc., pp. 254-273.

Briggs, G.G., Bromilow, R.H., Evans, A.A., 1982. Relationships between lipophilicity and root uptake and translocation of non-ionised chemicals by barley. Pestic. Sci. 13, 495-504.

Burkart, M.R., Kolpin, D.W., 1993. Hydrologic and land-use factors associated with herbicides and nitrate in near-surface aquifers. J. Environ. Qual. 22, 646-656.

Burken, J.G., Schnoor, J.L., 1997. Uptake and metabolism of atrazine by poplar trees. Environ. Sci. Technol. 31, 1399-1404.

Chiou, C.T., Sheng, G., Manes, M., 2001. A partition-limited model for the plant uptake of organic chemicals from soil and water. Environ. Sci. Technol. 35 , 1437-1444.

Harris, C.R., Sans, W.W., 1967. Absorption of organochlorine insecticide residues from agricultural soils by root crops. J. Agri. Food Chem. 15, 861-863.

Li, H., Sheng, G., Sheng, W., Xu, O., 2002. Uptake of trifluralin and lindane from water by ryegrass. Chemosphere $48,335-341$.
Li, H., Sheng, G., Chiou, C.T., Xu, O.Y., 2005. Relation of organic contaminant equilibrium sorption and kinetic uptake in plants. Environ. Sci. Technol. 39, 4864-4870.

Paterson, S., Mackay, D., McFarlane, C., 1994. A model of organic chemical uptake by plants from soil and the atmosphere. Environ. Sci. Technol. 28, 2259-2266.

Riederer, M., 1990. Estimating partitioning and transport of organic chemicals in the foliage/atmosphere system: discussion of a fugacity-based model. Environ. Sci. Technol. 24, 829-837.

Schroll, R., Bierling, B., Cao, G., Dorfler, U., Lahamiati, M., Langenbach, T., Scheunert, I., Winkler, R., 1994. Uptake pathways of organic chemicals from soil by agricultural plants. Chemosphere 28, 297-303.

Simonich, S.L., Hites, R.A., 1994. Vegetation - atmosphere partitioning of polycyclic aromatic hydrocarbons. Environ. Sci. Technol. 28, 939-943.

$\mathrm{Su}$, Y.H., Zhu, Y.G., 2006. Bioconcentration of atrazine and chlorophenols into roots and shoots of rice seedlings. Environ. Pollut. 139, 32-39.

Su, Y.H., Zhu, Y.G., Du, X., 2005. Co-uptake of atrazine and mercury by rice seedlings from water. Pestic. Biochem. Physiol. 82, 226-232.

Trapp, S., 1995. Model for uptake of xenobiotics into plants. In: Trapp, S., McFarland, J.C. (Eds.), Plant Contamination: Modeling and Simulation of Organic Chemical Processes. Lewis Publishers, Boca Raton, FL, pp. 107-151.

Trapp, S., 2004. Plant uptake and transport model for neutral and ionic chemicals. Environ. Sci. Pollut. Res. 11, 33-39.

Trapp, S., Matthies, M., 1995. Generic one-compartment model for uptake of organic chemicals by foliar vegetation. Environ. Sci. Technol. 29, 2333-2338.

Walker, A., 1972. Availability of atrazine to plants in different soils. Pestic. Sci. 3 , 139-148.

Weiss, P., 2000. Vegetation/soil distribution of semivolatile organic compounds in relation to their physicochemical properties. Environ. Sci. Technol. 34, 17071714.

Wild, E., Dent, J., Tomas, G.O., Jones, K.C., 2005. Direct observation of organic contaminant uptake, storage, and metabolism with plant roots. Environ. Sci. Technol. 39, 3695-3702.

Wild, E., Dent, J., Thomas, G.O., Jones, K.C. 2006. Visualizing the air-to-leaf transfer and within-leaf movement and distribution of phenanthrene: further studies utilizing two-photon excitation microscopy. Environ. Sci. Technol. 40, 907-916. 